\title{
Using the LMDI method to analyze the change in greenhouse gas emissions in Turkish sectors
}

\author{
Abdulkadir Bektas \\ The Ministry of Energy and Natural Resources, Nasuh Akar Mah. Türk Ocağı Cad. No:2 \\ 06520 Cankaya - Ankara / Turkey
}

\begin{abstract}
In this study, CO2 emissions of the Turkish economy are decomposed for the 1998-2017 period for four sectors; agriculture, forestry and fishery, manufacturing industries and construction, public electricity and heat production, transport, and residential. The analyses are conducted for five fuel types; liquid, solid, gaseous fuels, biomass, and other fuels. In decomposition analysis, Log Mean Divisia Index (LMDI) method is used. The analysis results point out that energy intensity is one of the determining factors behind the change in $\mathrm{CO} 2$ emissions, aside from economic activity. The fuel mix component, especially for the manufacturing industries and construction sector, lowers $\mathrm{CO} 2$ emissions during the crisis periods when the economic activity declines. Mainly, it is found that changes in total industrial activity and energy intensity are the primary factors determining the changes in $\mathrm{CO} 2$ emissions during the study period. Among GDP sectors, manufacturing industries and construction and public electricity and heat production are the two sectors that dominate the change in $\mathrm{CO} 2$ emissions. Additionally, the residential and transport sectors' contributions have gained importance during recent years. Among the manufacturing industries and construction, the non-metallic minerals sector contributes to $\mathrm{CO} 2$ emissions, followed by the chemicals sector.
\end{abstract}

Keywords: GHG emissions, decomposition analysis, LMDI Method, Turkey

\section{Introduction}

Numerous studies have shown the inevitable trend of global warming [1] if population growth and carbon emissions continue to grow at the current level, global temperature will rise in the range of 1.6 up to 5.8 degrees Celsius by the end of 21 st century. As the major constituent of 
greenhouse gas, the reduction of $\mathrm{CO} 2$ emissions especially from fossil fuels is a top priority in curbing global warming. In order to achieve emission reduction targets, it is necessary to investigate the drivers of $\mathrm{CO} 2$ emissions change of Turkey high energy intensive industries.

According to scientists, the increasing rate of carbon dioxide $\left(\mathrm{CO}_{2}\right)$ in the atmosphere created by the huge rising in the world population and economy is one of the most important causes of global warming. This has resulted in a massive concentration of atmospheric carbon dioxide, methane and nitrous oxide in the last 800,000 years at least. From 800,000 to 10,000 years ago, $\mathrm{CO}_{2}$ concentration in the air has ranged from 200 to 300 parts per million (ppm). It ranged from 275 to $285 \mathrm{ppm}$ from that period to the end of the $19^{\text {th }}$ century. Then it started to rise. It was up 297 ppm. In 1900. In 1958, it stopped at $315 \mathrm{ppm}$. The trend of increase continued and reached to $360 \mathrm{ppm}$ in 1995 and unfortunately, to $378 \mathrm{ppm}$ in 2005 . It reached e record of $406.84 \mathrm{ppm}$ in August 2018, a rate not seen for 3 million years. The outcome is not only the Earth is getting hotter, yet that it is doing so quicker than any time ever before. Until the 1950s, the rate of increase was $1 \mathrm{ppm}$ per year, but this rate increased to $2-2.5 \mathrm{ppm}$ per year in the early $2000 \mathrm{~s}$. This result is not only done the Earth warms up, but it does it faster than ever [[2], [3]]. Continued emissions of greenhouse gases would result in further heating and long-term changes in all components of the climate system, increasing the probability of extreme, omnipresent and inevitable effects on humans and the environment[3]

Turkey joined United Nations Framework Convention on Climate Change (UNFCCC) in 2004 and ratified Kyoto Protocol in 2009. As an Annex I party to the Convention, Turkey is required to develop annual inventory reports on emissions and removals of greenhouse gases not controlled by the Montreal Protocol using Revised 2006 IPCC Guidelines, Good Practice Guidance and Uncertainty Management in National Greenhouse Gas Inventories[4]. Though the required contents and timetable for their submissions for Annex I and non-Annex I parties differ, all parties must submit national reports on the implementation of the Convention. Turkey submitted her First National Communication on 20/02/2007 and the Fifth National Communication on 17/12/2013. These reports provide a data base of emissions and fuel use that are consistent with international standards.

As a result of carbon intensive growth policies Turkey has increased her greenhouse gas emissions rapidly. Specifically, overall greenhouse gas emissions expressed in $\mathrm{CO} 2$ equivalent have increased from 218.2 million tons in 1990 to 459.1 million tons in 2013. This corresponds to $110.4 \%$ increase throughout this time period and these figures do not include Land Use LandUse Change and Forestry (LULUCF) [2]. In terms of 2013 carbon dioxide equivalent emissions 
excluding LULUCF, the energy sector has the largest share with $67.8 \%$, followed by the industrial processes and product use with $15.7 \%$, the agriculture with $10.8 \%$ and the waste with $5.7 \%$ [2]. CO2 emissions per capita were $6.04 \mathrm{t}$ in 2013, while it was $3.96 \mathrm{t}$ for the year 1990 [3]. Per capita electricity consumption and per capita greenhouse gas emission levels in Turkey are about one third of those in other OECD countries. On the other hand, the energy intensity of the Turkish economy is higher than that of other OECD countries nearly by one third [4]. The major source of greenhouse gases is fossil fuel combustion; and energy sector is the main responsible sector in terms of emission of greenhouse gases in Turkey. Considering greenhouse gas emissions (excluding LULUCF) the energy sector's share is $70.2 \%$ in 2017. This number increases to $82.2 \%$ in terms of $\mathrm{CO} 2$ emissions [2]. The highest proportion of $\mathrm{CO} 2$ emissions from fuel combustion is from energy industries (public electricity and heat production, petroleum refining and manufacture of solid fuels) both in 1990 (27\%) and 2013 (37\%) [2]. Considering Turkey's ambitious growth perspective that does not take environmental impact of emissions into account, analyzing the sources of emissions is an important issue for developing alternative policy proposals.

Energy intensity (TPES divided by GDP) is around the OECD average. Turkey's target to reduce energy intensity by $20 \%$ by 2023 (from 2011) requires additional efforts to be reached (IEA,2016) (Chapter 4). TPES intensity has decreased to $96 \%$ of the 2005 value, whereas total final consumption intensity has decreased more $(88 \%)$. The decrease in energy intensity is, however, nor steady. It remains dependent on external economic conditions, as the effect of the 2008-09 global financial crisis [5].

\section{Literature review}

The decomposition Analysis (IDA) which utilizes index number computations is used to analyze the effects of $\mathrm{CO} 2$ emissions on the economy both at the aggregate level and at the sectoral level, specifically on the manufacturing and construction sector. Log Mean Divisia Index (LMDI) method developed by Ang [6] is employed to investigate the leading factors that cause the change in Turki In this study, among available methods the LMDI method developed by Ang [1] is used to figure out the leading factors that contribute to the change in $\mathrm{CO} 2$ emissions in the Turkish main four combustion sectors. Researchers and policy-makers use various decomposition methods to quantify the impact of different factors on the change of $\mathrm{CO} 2$ emissions. However, there is no consensus among them as to which is the "best" decomposition method. The first model was proposed in 1997 and the term "LMDI" was 
introduced a year later in 1998. The two methods, LMDI-I and LMDI-II, were only formally introduced in 2001. The LMDI decomposition approach comprises two different methods, LMDI-I and LMDI-II. The difference between them lies in the weights formulae used. In each case, several decomposition models have been reported. The popularity of the LMDI approach stems from a number of desirable properties it possesses (Ang, 2004). A practical guide to LMDI-I, based on the change of Canada's industrial energy consumption and $\mathrm{CO} 2$ emission was reported in Ang (2005). Ang, has underlined that decomposition analysis is a subject area that has gained in importance in policymaking in the energy field in the last 40 years. He compared various index decomposition analyses, and recommended that the multiplicative and additive LMDI I method, due to its theoretical foundation, adaptability, ease of use and result interpretation and some other desirable properties in the context of decomposition analysis. With LMDI now firmly established as the preferred approach in IDA, it is timely to conduct stocktaking by providing a precise and definitive documentation of the various LMDI models, including their origin, basic formulae, and key features. This will help potential users to make sensible choices and decisions when implementing it in their studies.sh economy's $\mathrm{CO} 2$ emissions.

In a previous study by Akbostanc1 et al. [7] evaluated GHG from production sector of Turkey that covers fifty seven sectors of Turkey by application the LMDI method and defined that industrial development varieties and intensity of energy are the primary key drivers of alterations in greenhouse gases. Coal is the crucial determinant in fuels, while steel and iron industry sectors are the most polluting industry-dominating $\mathrm{CO}_{2}$ emissions in the production sector of Turkey.

In the earlier studies, the computation of $\mathrm{CO} 2$ emissions was based on available energy statistics and emission factors from the Intergovernmental Panel on Climate Change (IPCC). The underlying energy statistics, however, did not include enough sectoral and technological detail to allow for a precise calculation of emissions. Turkey's First National Communicationwas published in 2007 and GHG inventory submissions to the UNFCCC have been annually reported since then. The national GHG inventory reports provide the official emission database for Turkey, consistent over time and consistent with international standards. This accurate and reliable data source for $\mathrm{CO} 2$ emissions has been employed in the current analysis.

Lise [8] explores development trajectories of four sectors but decomposes emissions at the aggregate level; Tunç et al. [9], the other hand, differentiate three sectors and decompose at sectoral level but aggregate transportation, housing and services under the service sector. The 
subsectors, however, differ significantly in terms of their technological infrastructure and have diverging intensity/scale/composition effects on emission growth which cannot be captured in an aggregate analysis. This study is done at a more disaggregate level; five sectors are distinguished and the decomposition analysis is employed on each sector separately.

Gonzalez and Martinez [10] performed a decomposition study to describe the forces that affected the alteration in the greenhouse gas in entire Mexico's industry and its 16 critical industrial sub-divisions throughout the period 1965-2003. They found the impacts of activity, composition, and fuel mix for electricity generation led to increasing $\mathrm{CO}_{2}$ emissions from 1965 to 2003 , respectively, they were mitigated by energy intensity and end-use fuel mix. Zhang et al. [11], Emodi et al. [12], and Sumabat et al. [13] used the LMDI decomposition technique to analyses $\mathrm{CO}_{2}$ emissions from power production in China, Nigeria and Philippine. They noticed that the most crucial contribution to rising $\mathrm{CO}_{2}$ emissions from power production is the effect of economic activity. Economic activities and energy intensity are the primary but adverse effects of energy-related carbon emissions. Thus, while financial activities increase energyinduced carbon emissions, energy intensity has a decreasing effect. The Industry and its subsectors are energy-intensive sectors and hence produce significant carbon emissions. Therefore, scholars have done much scientific research on the decomposition analysis of the industry.

Lise [8] also found that relatively rapidly growing economies, the most significant key driver in raising $\mathrm{CO}_{2}$ emissions is economic development. In contrast, the decreasing energy intensifies of the economy is accounted for a small decline in $\mathrm{CO}_{2}$ emissions in Turkey during the period 1980-2003.

Akbostanc1 et al.[14] have analyzed $\mathrm{CO}_{2}$ emissions of 5 industrials of the Turkish economy between 1990 and 2013. These sectors are; manufacturing, electricity and heat production, transportation, and residential industries. They found that the intensity of energy and wealth generation are the major factors of $\mathrm{CO}_{2}$ emission change. The first two sectors (MC and electricity) are the main crucial sectors that prevail in the alteration in GHG emissions. Furthermore, particularly for the MC sector, the fuel mixture component reduces the $\mathrm{CO}_{2}$ emissions during the times of economic downturn.

Tunç et al. [9] also used the LMDI method to identifying the crucial variable of 3 major indutries of Turkey (farming, production and facilities) GHG emissions. Tunç and his colleagues decomposed and analyzed GHG emissions of Turkey for 1970-2006 for examining the impacts of various macroeconomic policies on GHG emissions employing alteration in a portion of manufacturing and the usage of distinct energy resources. The investigation 
concluded that the primary increase in greenhouse gases is economic growth. In contrast, energy intensity brings down $\mathrm{CO}_{2}$ in 1980-1990 and 1995-2008 periods, and the industrial system is not a significant factor in minimizing carbon dioxide. Moreover, taking into account the contributions of sectors to $\mathrm{CO}_{2}$ emission changes, it was also found key drivers in $\mathrm{CO}_{2}$ emissions; the industry and services industries as predicted. The industry's contribution has increased in the latest years.

Rüstemoğlu [15] aims to identify and analysis by means of a technique of LMDI decomposition the factors which increase or decrease CO2 emissions for Turkey and Iran from 1990 to 2011. Economic growth and workforce are the major sources of $\mathrm{CO} 2$ emissions both in nations.. Surprisingly, the impact of energy intensity could be the third significant determining factor in Iranian carbon emissions. In contrast, it has a minimal lower impact on Turkey.

Ediger and Havuz [16] utilized the LMDI approach to Turkish sectoral power use evaluation beetween 1980-2000. Although there is a positive correlation among energy demand and the economic output, estimation that the sector specific energy usage differs significantly over the periods 1982, 1988-1989, 1994, and 1998-2000. Such policies would include improvements in the composition of final energy needs, improved material, and energy quality, and the replacement of more suitable products and oils.

Chontanawat et al. [17] also used the LMDI method to decompose the Thai manufacturing sector's source of changes in the level of $\mathrm{CO}_{2}$ emissions and the rate of $\mathrm{CO}_{2}$ emissions for the period 2005-2017. They found that the level of $\mathrm{CO}_{2}$ emissions and the intensity of $\mathrm{CO}_{2}$ emissions increased yearly on average during this timeframe. The effect of the systemic change led to alleviate both the sum of $\mathrm{CO}_{2}$ pollution and the emission intensity. However, the rising energy production of each enterprise increased the sum of $\mathrm{CO} 2$ emissions and the rate of $\mathrm{CO}_{2}$ emissions. The study, therefore, argues for strategies to curb the energy density of enterprises in industries to Thailand can profit through growing without having to incur pollutants furthermore.

Trotta [18] has isolated and quantified energy savings generated by improvements in energy efficiency from factors influencing the variance in Finland's final energy consumption between 2005-2015 by using a multi-sectoral LMDI-I decomposition method. Statistics show that efficiency saved 0.58 Mtoe (million tonnes of oil equivalent) of final energy from 2005 to 2015; the final energy usage in 2015 would've been 2.4 per cent higher without changes in the energy efficiency between 2005 and 2015. The savings estimated with the LMDI are substantially 
smaller relative to the energy consumption savings reported by the Finnish Government to the European Commission.

Shao et al. [19] have used the LMDI model. Tapio decoupling model and an emission estimation technique to predict to analyze the related decoupling and its impact influence the growth of China's commercial aviation and pollution, along with estimate predicted $\mathrm{CO}_{2}$ pollution. They found that cumulative greenhouse gases change over time on a generally ascending tendency, but there is consistent downward tendency oil consumption per tonnekilometer revenue. The transportation quantities growth impact is contributing effect to increased $\mathrm{CO}_{2}$ pollution among the four main drivers; accompanied by changes in the transport structure and alternate fuel effects. The "pace of energy consumption" aspect plays an essential part in hindering $\mathrm{CO}_{2}$ emissions. They also ended up estimating that China's commercial aviation would be accountable for $0.13 \mathrm{Gt}$ of $\mathrm{CO}_{2}$ emissions by 2020 depending on eight simulations. A factor of 1.6 to 3.9 could raise $\mathrm{CO}_{2}$ emissions between 2020 and 2050 .

Shao et al. [20] have used LMDI to factors influencing the usage of natural gas in every province in China. Generally, the primary critical factors of natural gas usage are the financial impact and the impact of the fossil fuel energy sector. The analyzes show that the effect on energy intensity is one of the critical restricting drivers for natural gas consumption; the most significant key drivers for natural gas usage in the net spillover block is the economic impact, followed by spatial expansion. They also found that low energy performance is a significant impediment to the growth of the Xinjiang and Ningxia natural gas sectors. The effect of population density is a significant driver leading to a discrepancy between Beijing and Shanghai in the market competition for natural gas. They concluded that it is particularly significant to prepare reasons for the growth of the natural gas sector to attain the energy transition targets and propose that the Chinese government increasing tax transfer payments, help net spillover growth.

Zhang et al. [21] analyze the influence of four drivers on overall $\mathrm{CO}_{2}$ emission increases, namely the effect of carbon density, the effect of energy intensity, the GDP per capita, and the economic impact of the population. The study reveals that the effect of GDP per capita is the primary factor behind increased $\mathrm{CO}_{2}$ emissions. The carbon concentration and the impact of the population also play a role here. The intensity of carbon has strongly significantly contributed to the decline in $\mathrm{CO}_{2}$ emissions in almost all the nations studied. In $\mathrm{C}$, carbon policies were aimed to decomposition financial development from ecological pressure. Energy policies need to increase the proportion of renewable energy sources in China and the ASEAN 
countries, raising energy efficiency, and introduce ecological growth as lengthy-term goals in the countries to decouple financial development from ecological repression.

Zhang et al. [22] have used the LMDI to decompose the Chinese manufacturing. The key drivers illustrated various effects on different manufacturing categories (or subsectors) and rates due to the variations in the industrialization stage, growth type, manufacturing investment, and research and development spending. Thus this analysis both discussed the general level of the manufacturing industry and explored the key drivers in each stage of economic development from the perspectives of the market segment and industry category.

Qian et al. [23] has applied the LMDI decomposition approach is utilized to evaluate the key drivers behind industrial $\mathrm{SO}_{2}$ pollution. The research phase is categorized through four phases, depending on the decoupling results: 1996-2001, 2001-2006, 2006-2010, and 2010-2015. They have found that $\mathrm{SO}_{2}$ generation strength and $\mathrm{SO}_{2}$ reduction are the key drivers to the reduction of manufacturing $\mathrm{SO}_{2}$ emissions while the primary inhibitory factor is the effect of economic activity. Besides, in some of these areas, the economic structure and the strength of the $\mathrm{SO}_{2}$ generation indicate negative contributions to rising industrial $\mathrm{SO}_{2}$ emissions.

Song et al. [24] examined the decoupling state and reduction capacity of emissions from the transportation industry throughout the 1991-2015 period. Their study uses the technique of LMDI to classify influential drivers that control emissions of this sector in China. While economic development drivers have raised the emissions, the $\mathrm{CO}_{2}$ coefficient impact has decreased emissions. Over the period 1991-2015, extensive coupling (EC) with economic development posed $\mathrm{CO}_{2}$ emissions from China's transportation sector.

Fang et al. [25] has showed that the conomic development has been found to have a substantial impact on energy consumption, while technological development can efficiently mitigate it. Furthermore, the outcomes of analyzing electricity usage from an industrial and regional context demonstrate that the economic system and intensity of usage have different effects in the eastern, central, and western regions.

Li et al.[26] examined the spatial pattern progression of transport emissions in China from 2005 to 2015, after analyzing the emissions from transport in China's 341 regions. Depending on index decomposition evaluation, GDP per capita and population increases were the most significant factors affecting emission rising, respectively. Transportation carbon emissions per GDP was, however, a determinant of emissions reductions. 
Jiang et al. [27] have considered that economic development is the key factor affecting the increasing energy consumption in non-housing regions. Besides, the increased energy consumption rate as a second key factor reduces the growth of non-housing electricity usage. Finally, growth in the population as the third factor has a low impact on rising electricity usage. Jiang et al. [28] used the LMDI method to describe the main factors of energy consumption. They found that foreign trade development, economic growth, and inhabitants are due to increased use of embodied energy. Conversely, the modernization and optimization of industrial systems and structures would support to reduce the growth of embodied energy usage. A specific Investigation is under way on the Turkish high - intensity combustion sector in 4 categories with the use of LMDI in order to achieve emission reductions goals in order to achieve a low-carbon transition in Turkey.

\section{Methodology and data}

\subsection{The Log-mean Divisia Index Method}

In this study Ang [6] used the LMDI technique to disintegrate the key drivers of $\mathrm{CO} 2$ emissions from four fuel types in the Turkey four major ignition industries.

$C=\sum_{i j} C_{i j}=\sum_{i j} Q \frac{Q_{i}}{Q} \frac{E_{i}}{Q_{i}} \frac{E_{i j}}{E_{i}} \frac{C_{i j}}{E_{i j}}=\sum_{i j} Q S_{i} I_{i} M_{i j} U_{i j}$

Where $\mathrm{C}$ is the energy-related total $\mathrm{CO} 2$ emissions (Unit: 103 tons) of Turkish four high-energy intensive industries; $i$ denotes the $i$-th energy intensive sector; $j$ denotes the $j$-th type of energy; C_ij is the $\mathrm{CO} 2$ emissions contributed by the $\mathrm{j}$-th type of energy consumed by $\mathrm{i}$-th sector (Unit: 103 tons $), Q\left(=\sum\right.$ w.E. $\left.\mathrm{Q} \_\mathrm{i}\right)$ is the total economic activity level, $\mathrm{Q} \_\mathrm{i}$ is the value added of $\mathrm{i}$-th sector, E_ $\mathrm{i}\left(=\sum \sum_{\text {w.w. }} \mathrm{E}_{-} \mathrm{ij}\right)$ is the energy consumption of $\mathrm{i}$-th sector, and the unit of this variable is TJ (109 $\mathrm{kj}$ ), $\mathrm{E} \_\mathrm{ij}$ is the consumption of fuel $\mathrm{j}$ in sector $\mathrm{i}$.

Where $\mathrm{Si}(=\mathrm{Qi} / \mathrm{Q})$ is the share of sector and represent the industrial structure, $\mathrm{Ii}(=\mathrm{Ei} / \mathrm{Qi})$ is the energy intensity of sector $\mathrm{i}$; the fuel-mix variable is given by Mij (=Eij/Ei) and $\mathrm{Uij}(=\mathrm{Cij} / \mathrm{Eij})$ denotes the $\mathrm{CO} 2$ emissions coefficient of energy $\mathrm{j}$ consumed by $\mathrm{i}$-th industry.

Let $\mathrm{V}$ be an energy-related aggregate. Assume that there are $\mathrm{n}$ factors contributing to changes in $\mathrm{V}$ over time and each is associated with a quantifiable variable whereby there are $\mathrm{n}$ variables, $\mathrm{x} 1$; $\mathrm{x} 2$; $\mathrm{y}$; $\mathrm{xn}$ : Let subscript $\mathrm{i}$ be a sub-category of the aggregate for which structural change is 
to be studied. At the sub-category level the relationship Vi =x1,i x2,i....xn,i holds. The general index decomposition analysis (IDA) identity is given by

$V=\sum_{i} V_{i}=\sum_{i} x_{1, i} x_{2, i} \ldots \ldots x_{n, i}$

The aggregate changes from $\mathrm{V}^{0}=\sum_{i} x^{0}{ }_{1, i} x^{0}{ }_{2, i} \ldots \ldots x^{0}{ }_{n, i}$ in period 0 to $\mathrm{V}^{\mathrm{T}}=\sum_{i} x^{T}{ }_{1, i} x^{T}{ }_{2, i} \ldots x^{T}{ }_{n, i}$ in period $\mathrm{T}$,

In multiplicative decomposition, we decompose the ratio:

$D_{\text {tot }}=V^{T}-V^{0}=D_{x 1} D_{x 2} \ldots \ldots D_{x n}$

In additive decomposition, we decompose the difference:

$\Delta \mathrm{V}_{\mathrm{tot}}=\mathrm{V}^{\mathrm{T}}-\mathrm{V}^{0}=\Delta \mathrm{V}_{\mathrm{x} 1}+\Delta \mathrm{V}_{\mathrm{x} 2}+\ldots .+\Delta \mathrm{V}_{\mathrm{xn}}$

where subscript tot represents the total or overall change and the T and 0 attributed to timespan of $\mathrm{T}$ and 0 .

In the logarithmic mean Divisia index (LMDI) approach, the general formulae for the effect of the kth factor on the right-hand side of Equations (5) and (6) are respectively:

$D_{x_{k}}=\exp \left(\sum_{i} \frac{L\left(V_{i}^{T}, V_{i}^{0}\right)}{L\left(V^{T}, V^{0}\right)} \ln \left(\frac{x_{k, i}^{T}}{x_{k, i}^{0}}\right)\right)$

$=\exp \left(\sum_{i} \frac{\left(V_{i}^{T}-V_{i}^{0}\right) /\left(\ln V_{i}^{T}-\ln V_{i}^{0}\right)}{\left(V^{T}-V^{0}\right) /\left(\ln V^{T}-\ln V^{0}\right)} \ln \left(\frac{x_{k, i}^{T}}{x_{k, i}^{0}}\right)\right)$

$\Delta \mathrm{V}_{x_{k}}=\sum_{i} L\left(V_{i}^{T}, V_{i}^{0}\right) \ln \left(\frac{x_{k, i}^{T}}{x_{k, i}^{0}}\right)$

$$
=\sum_{i} \frac{V_{i}^{T}-V_{i}^{0}}{\ln \left(V_{i}^{T}-V_{i}^{0}\right)} \ln \left(\frac{x_{k, i}^{T}}{x_{k, i}^{0}}\right)
$$

Where $\mathrm{L}(\mathrm{a}, \mathrm{b})=(\mathrm{a}-\mathrm{b}) /(\ln \mathrm{a}-\ln \mathrm{b})$, where both $\mathrm{a}$ and $\mathrm{b}$ positive numbers and $\mathrm{a}=\mathrm{b}$ as defined in Ang, 2004 [29]. Therefore, the change of $\mathrm{CO}_{2}$ emissions from four combustion industries of Turkish economy between a base year o and a target year $\mathrm{t}$, denoted by $\Delta \mathrm{C}_{\text {tot }}$ under the LMDI can be decomposed into the five effects as follows; (i) the changes in the economic activity 
effect (denoted by $\Delta \mathrm{C}_{\mathrm{act}}$ ); (ii) the changes in the structure effect (denoted by $\Delta \mathrm{C}_{\text {str }}$ ); (iii) the changes in the sectoral energy intensity effect (denoted by $\Delta \mathrm{C}_{\text {int }}$ ); (iv) the changes in the sectoral energy-mix effect (denoted by $\Delta \mathrm{C}_{\text {mix }}$ ); and the changes in the emissions coefficient effect (denoted by $\Delta \mathrm{C}_{\mathrm{emf}}$ ) in additive form, as shown in Equation(7):

$\Delta \mathrm{C}_{\text {tot }}=C^{T}-C^{0}=\Delta \mathrm{C}_{\mathrm{act}}+\Delta \mathrm{C}_{\mathrm{str}}+\Delta \mathrm{C}_{\mathrm{int}}+\Delta \mathrm{C}_{\mathrm{mix}}+\Delta \mathrm{C}_{\mathrm{emf}}$

The LMDI formulae can be expressed as:

$\Delta \mathrm{C}_{\mathrm{act}}=\sum_{\mathrm{ij}} \frac{\mathrm{C}_{\mathrm{ij}}^{\mathrm{T}}-\mathrm{C}_{\mathrm{ij}}^{0}}{\ln \mathrm{C}_{\mathrm{ij}}^{\mathrm{T}}-\ln \mathrm{C}_{\mathrm{ij}}^{0}} \ln \left(\frac{\mathrm{Q}^{\mathrm{T}}}{\mathrm{Q}^{0}}\right)$

$\Delta \mathrm{C}_{\mathrm{str}}=\sum_{\mathrm{ij}} \frac{\mathrm{C}_{\mathrm{ij}}^{\mathrm{T}}-\mathrm{C}_{\mathrm{ij}}^{0}}{\ln \mathrm{C}_{\mathrm{ij}}^{\mathrm{T}}-\ln \mathrm{C}_{\mathrm{ij}}^{0}} \ln \left(\frac{\mathrm{S}_{i}^{\mathrm{T}}}{\mathrm{S}_{i}{ }^{0}}\right)$

$\Delta \mathrm{C}_{\mathrm{int}}=\sum_{\mathrm{ij}} \frac{\mathrm{C}_{\mathrm{ij}}^{\mathrm{T}}-\mathrm{C}_{\mathrm{ij}}^{0}}{\ln \mathrm{C}_{\mathrm{ij}}^{\mathrm{T}}-\ln \mathrm{C}_{\mathrm{ij}}^{0}} \ln \left(\frac{\mathrm{I}_{i}^{\mathrm{T}}}{\mathrm{I}_{i}{ }^{0}}\right)$

$\Delta \mathrm{C}_{\text {mix }}=\sum_{\mathrm{ij}} \frac{\mathrm{C}_{\mathrm{ij}}^{\mathrm{T}}-\mathrm{C}_{\mathrm{ij}}^{0}}{\ln \mathrm{C}_{\mathrm{ij}}^{\mathrm{T}}-\ln \mathrm{C}_{\mathrm{ij}}^{0}} \ln \left(\frac{\mathrm{M}_{i j}{ }^{\mathrm{T}}}{\mathrm{M}_{i j}{ }^{0}}\right)$

$\Delta \mathrm{C}_{\mathrm{emf}}=\sum_{\mathrm{ij}} \frac{\mathrm{C}_{\mathrm{ij}}^{\mathrm{T}}-\mathrm{C}_{\mathrm{ij}}^{0}}{\ln \mathrm{C}_{\mathrm{ij}}^{\mathrm{T}}-\ln _{\mathrm{ij}}^{0}} \ln \left(\frac{\mathrm{U}_{i j}^{\mathrm{T}}}{\mathrm{U}_{i j}{ }^{0}}\right)$

\subsection{Analysis of Data}

We investigate the driving forces of energy-related $\mathrm{CO}_{2}$ emissions change of Turkey four highenergy intensive combustion sectors covering 20 years. During the analysis the data used in the Turkish Greenhouse Gas Inventory 2017 and the CRF charts published to the UNFCCC were used for the decomposition analysis[4]. Data were obtained. The data set of the research consequently conforms to global practices.

The Ministry of Treasury and Finance provides data on Gross domestic product and economic development. Data on economic output statistics comes from the Ministry of Treasury and Finance, as well as World Bank statistics.

4. Analysis of driving forces of energy-related $\mathrm{CO} 2$ emissions of four combustion sectors 
Energy systems are for most economies largely driven by the combustion of fossil fuels. During combustion the carbon and hydrogen of the fossil fuels are converted mainly into carbon dioxide $\left(\mathrm{CO}_{2}\right)$ and water $\left(\mathrm{H}_{2} \mathrm{O}\right)$, releasing the chemical energy in the fuel as heat. This heat is generally either used directly or used (with some conversion losses) to produce mechanical energy, often to generate electricity or for transportation. The energy sector is usually the most important sector in greenhouse gas emission inventories, and typically contributes over 90 percent of the $\mathrm{CO}_{2}$ emissions and 75 percent of the total greenhouse gas emissions in developed countries. For the Turkish Republic, these numbers are $86,3 \%$ and $81 \%$ correspondingly in 2017. CO2 generally accounts for $95 \%$ of the methane- and nitrous oxide-related energy sector emissions. Static incineration is usually responsible for about $70 \%$ of the greenhouse gas emissions from the energy sector. About half of these emissions are associated with combustion in energy industries mainly electricity production and oil refinement [30].

\subsection{Primary Energy Usage}

Total primary energy use increased considerably during 1990-2007 as shown in Fig. 1. The average annual rate of increase was $7.0 \%$ in the electricity sector, $6.1 \%$ in the residential sector, $4.6 \%$ in the manufacturing sector, $4.0 \%$ in the transport sector and $3.6 \%$ in the agriculture sector. The highest volatility in sectoral energy use occurred in manufacturing. Thiswas a result of the strong relation to economic development. The primary energy use for manufacturing activities declined considerably in years of economic crisis, as experienced during 1994, 1999 and 2001 when GDP decreased by 5.5, 4.7 and 7.5 percent respectively. 


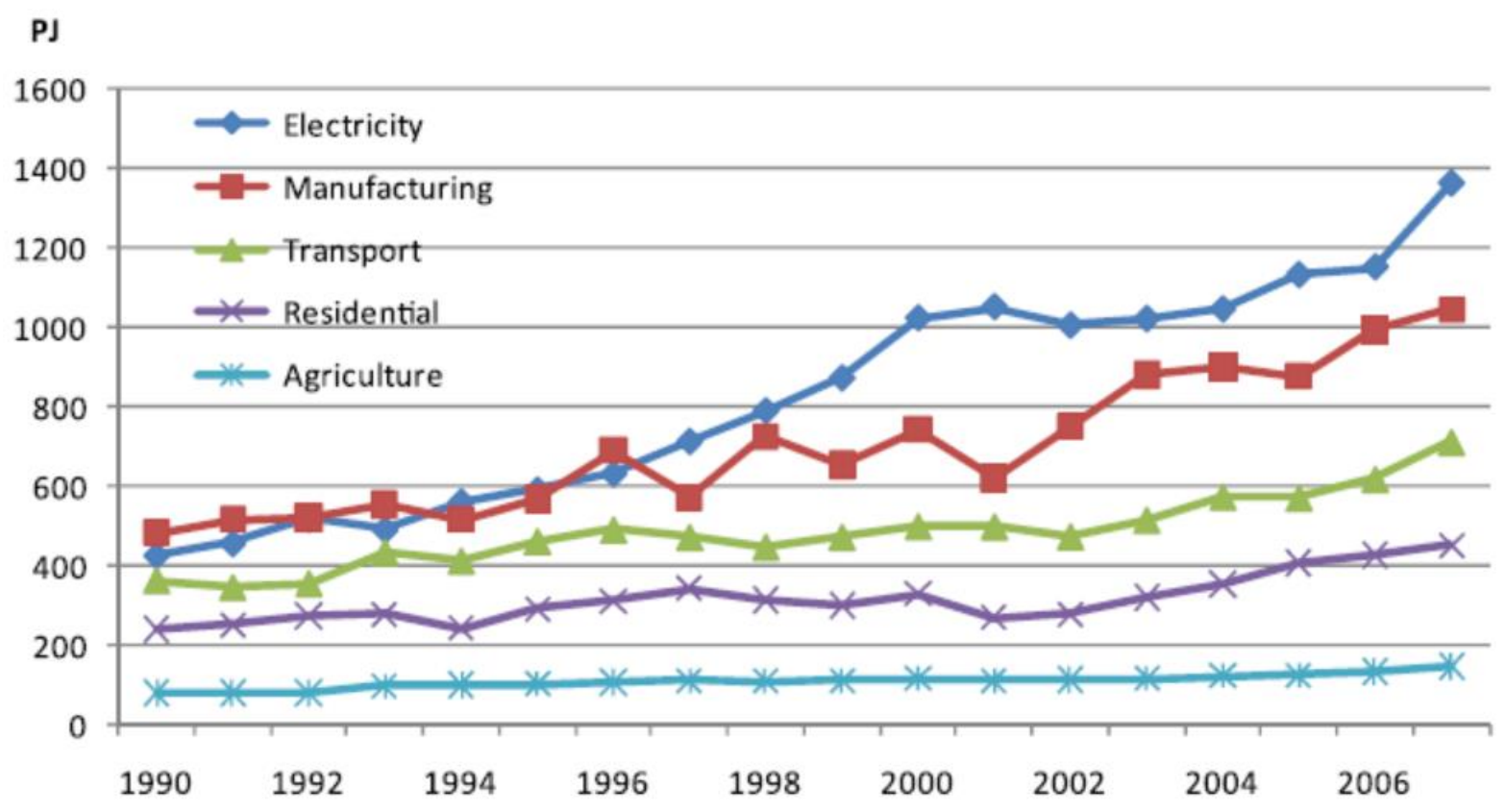

Fig. 1. Sectoral primary energy use 1990-2007.

The composition of primary energy use over 1990-2007 can be seen in Fig. 2(a) which indicates a rapid diffusion of gaseous fuels. Their average annual growth was 14.8\% over 1998-2018 whereas the growth of solid and liquid fuels was only $3.8 \%$ and $2.1 \%$ respectively. Hence, there was a compositional change away from gaseous fuels. The rapid growth of gaseous fuels was a result of accelerated natural gas consumption, which started with 0.4 billion cubic meters (bcm) in 1987, reached $3.2 \mathrm{bcm}$ in 1998 and increased to $36.5 \mathrm{bcm}$ in 2018 . Exactly $50 \%$ of the natural gas consumed in 2007 was used for electricity production $(27.5 \%$ for industrial and $22.5 \%$ for residential use). The use of primary energy sources for electricity production over 1998-2018 is depicted in Fig. 2(b). The average annual growth rate of gas for electricity corresponded to $12.4 \%$. Solid fuels grew by $4.1 \%$ per year, and liquid fuels by $3.6 \%$ per year over the same period [31]. 


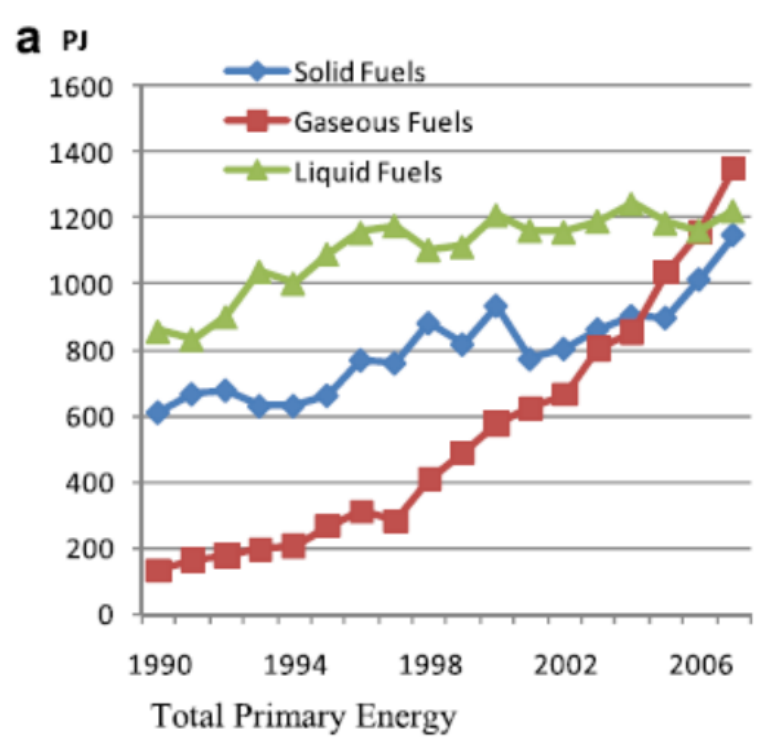

(a) Total primary energy, b PJ

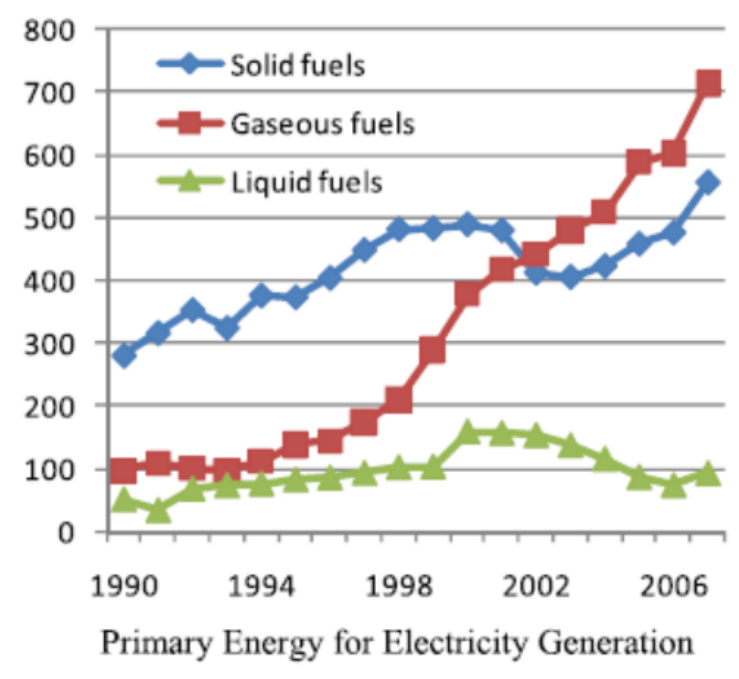

(b) primary energy for electricity generation

Fig. 2. Composition of primary energy 1990-2007.

4.2. The economic activity of Turkey

During 1990e2007, real GDP grew at an annual average rate of 4.4\%. However, the Turkish economy was hit by three years of contraction. In 1994, structural problems, including high budget deficits, skyrocketing interest and inflation rates plunged the economy into a recession when GDP declined by $5 \%$ in real terms. The following turnaround did not last long as the economy was affected in 1998 by the Russian financial crisis and domestic political turmoil. Conditions worsened in 1999 when general elections were held and the country was hit by a major earthquake - real GDP declined by $4.7 \%$ the same year. An economic crisis peaked in 2001, resulting in a sharp contraction of $7.5 \%$ as depicted in Fig. 3.

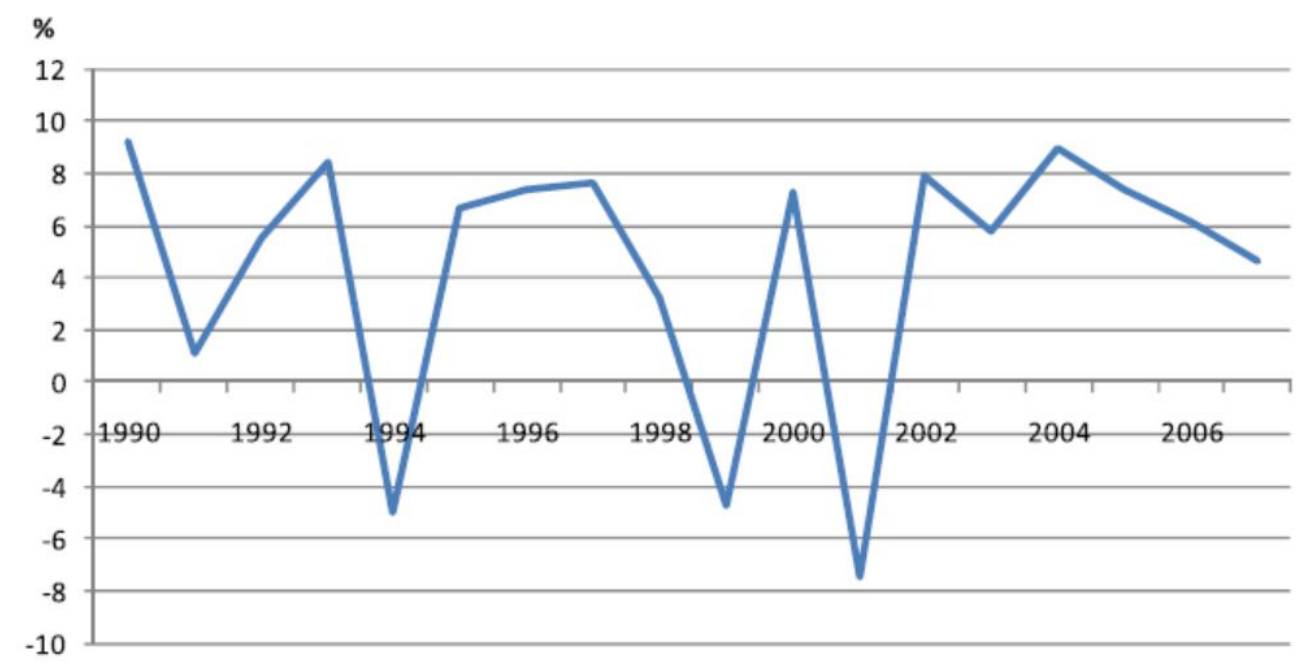


Fig. 3. Annual growth rates of real GDP in Turkey, 1990-2007.

The share of agriculture in GDP declined considerably from $16.4 \%$ in 1990 to $9.8 \%$ in 2007 whereas both industry and service gained relative importance: industry increased its value share from $26.2 \%$ in 1990 gradually to $29.4 \%$ in 2007 ; the service sector reached $60.8 \%$ in 2007 - up from $57.4 \%$ in 1990. An illustration of the sectoral GDP development is provided in Fig. 4.

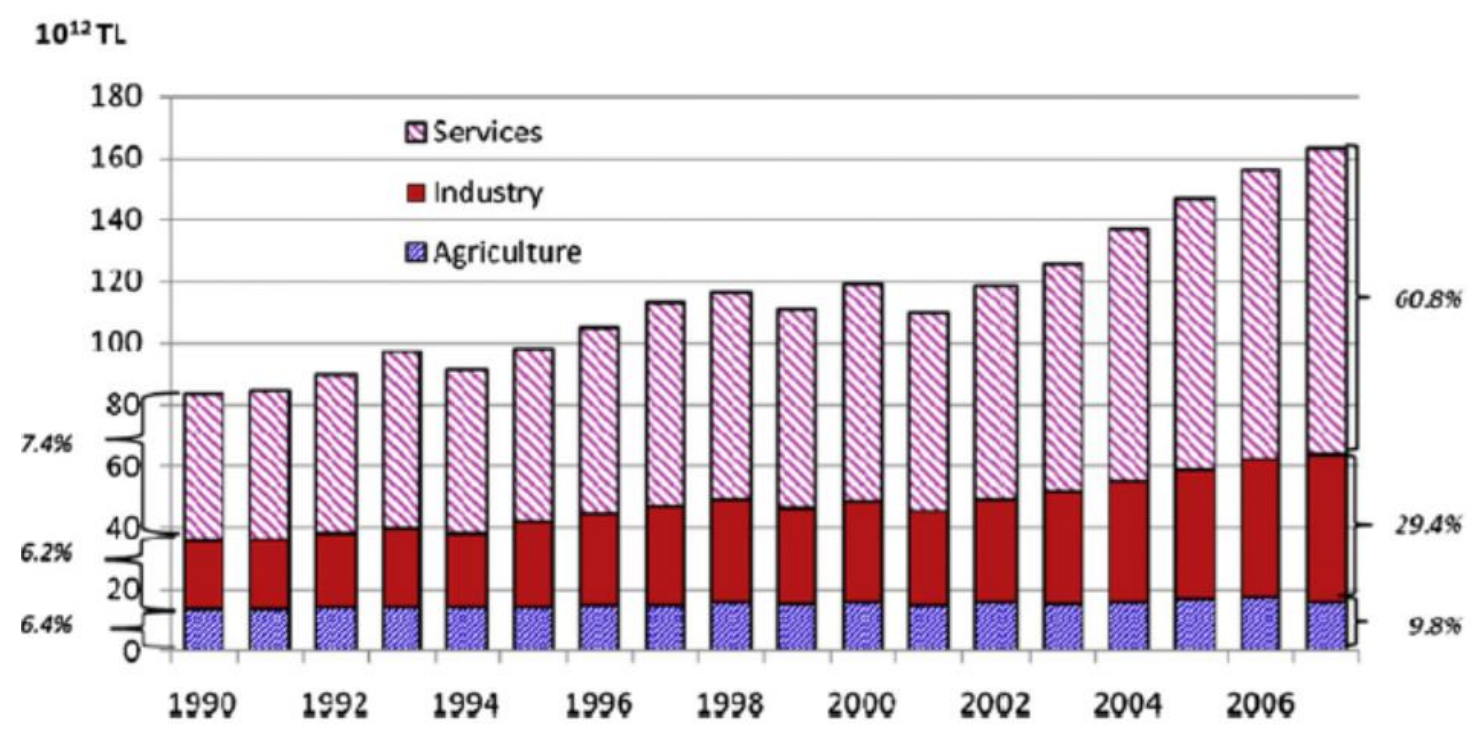

Fig. 4. 1990e2007 sectoral development of Turkish GDP (at 1987 constant prices)

The development of sectoral output in physical terms (joule, ton, ton-km) is depicted in Fig. 5.

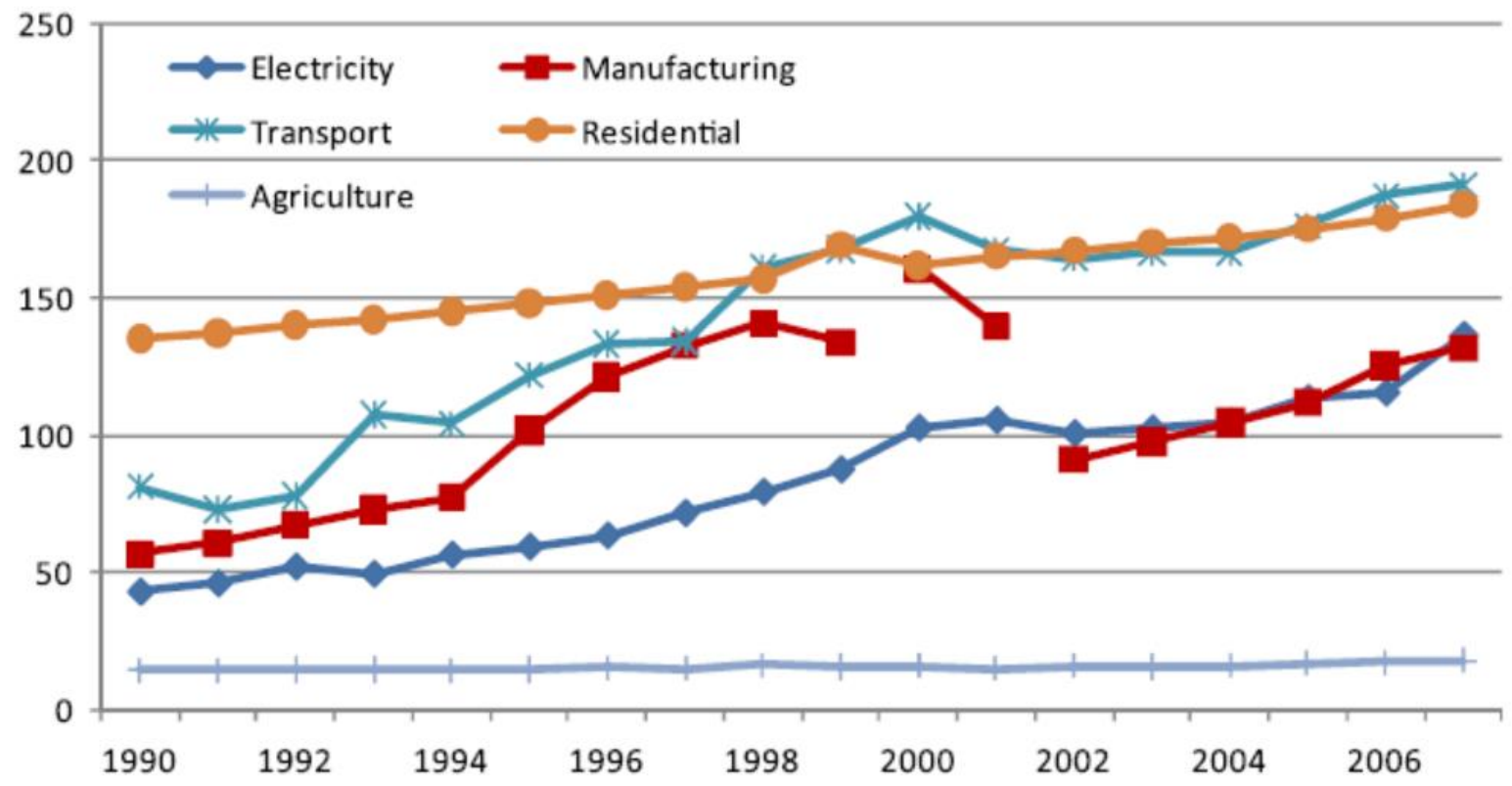

Fig. 5. 1990-2007 economic activity in Turkey 
It is observed that a sector's physical output trajectory is, in general, in correlation with the corresponding trajectory of sectoral GDP. If a sector's physical output increases, its sectoral GDP rises as well - and vice versa. Production data for the manufacturing sector has disruptions: no consistent and reliable data is available for petroleum refining before 2000 and non-ferrous metals after 2001. Therefore, the manufacturing data series is not comparable for the periods 1999-2001 and 2001e2002. And hence the manufacturing activity line in Fig. 5 is left unconnected for these periods. The decline in 2000-2001 is a result of the financial crisis that led to a contraction of the economy with far-reaching impacts on industrial output and employment. Impacts of the crisis were also observed in other economic sectors as evident in Fig. 5. The long-term average annual growth rates of sectoral economic activity during 19982018 were $7.0 \%$ in electricity production, $5.2 \%$ in transport, $1.8 \%$ in residential, $1.4 \%$ in agriculture, and 7.7e10.0\% in manufacturing (during 1990-1999 and 2002-2007 respectively).

\subsection{Energy (CRF Sector 1)}

The energy sector includes emissions from the combustion of fossil fuels (1.A.1 energy industries; 1.A.2 manufacturing industries and construction; 1.A.3 transport; and 1.A.4 other sectors ; as well as fugitive emissions from fossil fuels (1.B) and $\mathrm{CO} 2$ transportation and storage (1.C).

Energy sector is the major source of Turkish anthropogenic GHG emissions. Overall in 2017 GHG emissions (excluding LULUCF), the energy sector had the largest portion with $72.2 \%$. Total emissions from the energy sector for 2017 were estimated to be $380 \mathrm{Mt} \mathrm{CO} 2$ eq. of which 373.2 Mt CO2 eq. is coming from fuel combustion (98.2\%) and 6.7 Mt CO2 eq. is related to fugitive emissions from fuels. Energy industries subsector (1.A.1) were the main contributor, accounting for $155.0 \mathrm{Mt} \mathrm{CO} 2 \mathrm{eq}(40.8 \%)$ emissions from the energy sector. It is followed by transport (1.A.3) sector with $84.7 \mathrm{Mt}$ (22.3\%), other sector (1.A.4) with $73.4 \mathrm{Mt}$ (19.3\%) (Commercial / institutional / Residential with 60.2 Mt (16.6\%) and Agriculture/forestry/fishing with $10.2 \mathrm{Mt}$ (2.7\%) and manufacturing industries and construction subsector (1.A.2) with 60.2 Mt CO2 eq. (15.8\%) in the same year as shown in Figure 3 [2].

Figure-4 shows the shares of energy-related sectors' emissions in total $\mathrm{CO} 2$ emissions in Turkey from 1998 to 2017. The average share of Energy sector emissions in total CO2 emissions is $72.2 \%$ in Turkey. Manufacturing industries and construction sector has been fluctuated and finally declined from $20 \%$ to $11 \%$. The share of transport has been fluctuated and inclined from $12 \%$ to $16 \%$. Moreover, the others two main sectors 
commercial/institutional/residential and agriculture/forestry/fishing has been fluctuated $11 \%$ and $3 \%$ respectively.

Total emissions from the energy sector increased by $93.96 \%$ as compared to 1998 levels. The strongest rise in emissions has been in transport (by 158.2\%), commercial/institutional/residential services (by 119.4\%), while emissions from Agriculture, forestry, fishing and manufacturing industries and construction sector increased by $14.4 \%$ and $8.5 \%$, respectively.

\subsection{Manufacturing industries and construction (Category 1.A.2)}

This source category consists of manufacturing industries sectors. IPCC categorizes manufacturing industry as iron and steel, nonferrous metal, chemicals, pulp, paper and print, food processing, beverages and tobacco, non-metallic minerals and other industry. Until, 2015 sectoral breakdown of national energy balance tables are not fully in line with CRF categories. In the national energy balance tables, pulp, paper and print sector were presented separately from 2011 onward. It was presented under "other industries (1.A.2.g)" category before 2011. Food processing category included only sugar industry for 1990-2010 periods. From 2011 onward all food-processing industries were covered but beverages and tobacco industry were still included under "other industries (1.A.2.g)" category. However, starting from 2015, national energy balance tables are detailed and provided energy consumption for all economical activities so GHG emissions are allocated in line with CRF category [2].

As can be seen from the Table-2, there is a sharp decrease in the emissions in 2008. This is due to the global economic downturn in 2008. GHG emissions from 1.A.2 category is $60.2 \mathrm{Mt}^{\mathrm{CO}_{2}}$ eq. in 2017 which is $16.1 \%$ of total fuel combustion and $12.0 \%$ of total national emissions (excluding LULUCF), whereas GHG emissions from 1.A.2 category was 55.5 Mt CO2 eq. which is $29.0 \%$ of total fuel combustion and $20.0 \%$ of total national emissions (excluding LULUCF) in 1998. GHG emissions from 1.A.2 category have been increased by $4.71 \mathrm{Mt} \mathrm{CO}_{2}$ eq. $(8.5 \%)$ from 1998 to 2017.

\subsection{Transport (Category 1.A.3)}

This source category have five sub-categories; Domestic Aviation (1.A.3.a), Road Transportation (1.A.3.b), Railways (1.A.3.c), Domestic water-borne Navigation (1.A.3.d) and Pipeline (other transportation) (1.A.3.e.i). 
In 2017, transport sector contributed to $84.7 \mathrm{Mt} \mathrm{CO}_{2}$ eq. emissions. $\mathrm{GHG}$ emissions (in $\mathrm{CO}_{2}$ eq.) from transport sector, as a share of total fuel combustion was $22.7 \%$ in 2017 while it was $17.2 \%$ in 1998. During the period of 1998-2017, the strongest rise in emissions among the energyrelated sectors was in transport (by 158.2\%). GHG emissions from 1.A.3 category have been increased by $51.87 \mathrm{Mt} \mathrm{CO}_{2}$ eq. from 1998 to 2017.

GHG emissions by transport mode are given in Table 3 and the road transportation is the major $\mathrm{CO}_{2}$ source contributing to $93 \%$ of transport emissions in 2017. Contribution of domestic aviation is $4.5 \%$, domestic water-borne navigation is $1.1 \%$, and railways are $0.5 \%$ in 2017 . The share of pipeline transportation is $0.9 \%$.

\subsection{Commercial/Institutional/Residential (Category 1.A.4.a,b)}

The fuel consumption of commercial/institutional is not separated in the energy balance tables until 2015; it is given under residential sector for 1990-2014 period. Emissions are given under 1.A.4.a category in 2015 for the first time and they are included under (1.A.4.b) for 1990-2014 periods. In this paper, we have considered commercial/Institutional and Residential sectors as one sectors for period of 1998-2017. During the period of 1998-2017, the second strongest rising in emissions among the energy-related sectors was in this sector (by 137.6\%). GHG emissions from 1.A.4.a.b category have been increased by $36.18 \mathrm{Mt} \mathrm{CO}_{2}$ eq. from 1998 to 2017.

\subsection{Agriculture/Forestry/Fisheries (Category 1.A.4.c)}

The source category is only including the emission from the consumption of fuel in agricultural activities. The AD of this sub-category generally keeps consistency during the period 19902011, increasing gradually. However, there was a drop in 2012 due to classification problem with diesel oil consumption. After April 2011, it is not possible to separate the different use of diesel fuel. Therefore, in 2012 energy balance table, some of diesel oil used in agricultural sector is included in road transportation. Due to this fact, a sharp increase in diesel consumption in road transportation and a sharp decrease in fuel consumption of Agriculture/Forestry/Fisheries sector were observed.

More than $90 \%$ of GHG emissions from agricultural sector is related to off road vehicles. The share of $\mathrm{GHG}$ emissions as $\mathrm{CO}_{2}$ eq. from 1.A.4.c category in total other sectors is $13.9 \%$ in 2017 while it was $19.2 \%$ in 1990. Moreover, the GHG emissions from 1.A.2 category have been increased by $1.28 \mathrm{Mt} \mathrm{CO}_{2}$ eq. (14.4\%) from 1998 to 2017. 


\section{Analysis of energy-related GHG emissions}

In this section, initially the shares of sectors that are covered in the analysis are reviewed. A noticeable development in the study period is the decline in the share of agriculture, forestry and fisheries sector and the increase in the share of transport sector. The share of agriculture, forestry and fisheries has declined from $22 \%$ in 1998 to $16 \%$ in 2013 while the share of transport sector has increased from $16 \%$ to $21 \%$ during the same period. Share of manufacturing industries and construction on the other hand was 44\% in 1990 and increased to 52\% in 2013. Shares of residential and public electricity and heat production sectors are steady around $8 \%$ and $4 \%$, respectively, during the study period.

Manufacturing industry sectors that are covered in this study are the ones for which emissions data are available. Most of these are dirty industries that have relatively higher energy intensities. Overall, total share of these dirty industries in industrial production constitutes $32 \%$ as the period average. Among these sectors, food processing, beverages and tobacco has the highest share in manufacturing industries and construction sector's output, which is around $14 \%$ as the period average. This sector is followed by iron and steel, petroleum refining and pulp paper and print with average shares, 5.2\%,3\% and 2.9\%, respectively. Finally, chemicals and non-ferrous metals sectors have respective shares of $1.5 \%$ and $1 \%$ as the period averages.

An overview of the energy intensities of the sectors helps to evaluate the decomposition results. The energy intensities of the sectors show that for GDP sectors the highest energy intensity is realized in the public electricity and heat production sector, followed by the residential sector and the lowest energy intensity is observed in the agriculture, forestry and fisheries sector. Public electricity and heat production sector's energy intensity declines between 2001 and 2004, after that it increases until 2008 and later falls until 2013. Eventually, there is $9.4 \%$ decline in the energy intensity of the sector from 2001 to 2013. Overall, energy intensity in the economy declines by $50 \%$ from 2001 to 2012. Among GDP sectors only the residential sector can be given as a counter example to this general tendency; there is a steep increase in energy intensity after 2001 until 2009, overall constituting an increase of 20\% from 2001 to 2013. Energy intensity of manufacturing industry and construction sector has decreased by $47.6 \%$ from 2003 to 2012 . However, the energy intensities have increased by $52.6 \%$ in chemicals, $45.9 \%$ in nonmetallic minerals and $9.7 \%$ in petroleum refining from 2003 to 2012. In this period chemicals and non-metallic minerals have the highest average energy intensities. Non-ferrous metals sector was the second highest energy intensive sector between 2003 and 2007After 2007 
due to a $50.6 \%$ decline in its energy intensity, the sector became the fifth falling behind the iron and steel sector. Iron and steel and food processing, beverages and tobacco sectors are the other sectors that have experienced respective declines of $12.2 \%$ and $11.2 \%$ in energy intensities during this period.

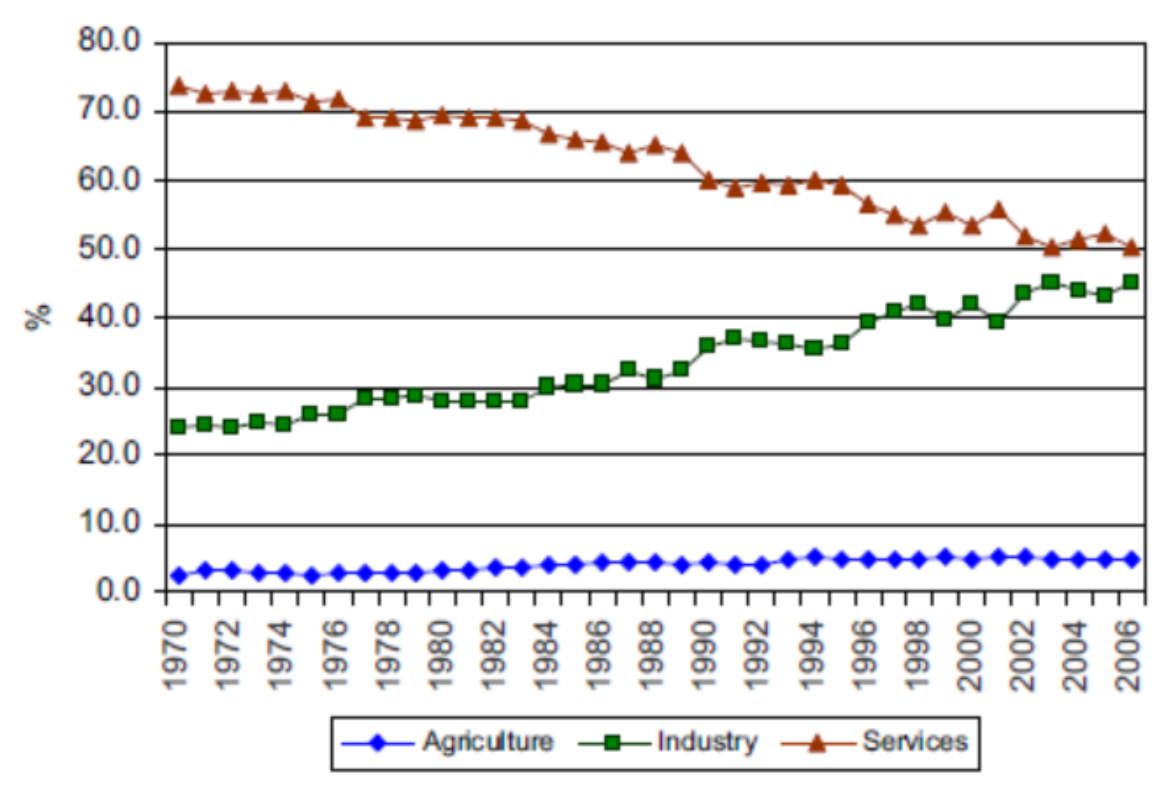

Fig. 6. Shares of sectors in total $\mathrm{CO} 2$ emissions

\subsection{Fiscal impact of activity::}

Before presenting the decomposition analysis results we discuss the general characteristics of the Turkish economy and its energy use during the study period. General trend of the economic activity in the Turkish economy can be followed from Fig. 7. It is apparent that the volatility of the Turkish economy is more in the 1990s compared to the 1970s and 1980s. From the real GDP series the impact of economic and political crisis of 1980 is seen as a slow down in the economy. However,when we look at the exchange rate crisis of 1994, the slow down of 1998 and financial crisis of 2001 , it can be realized that impacts of these turmoil on the economic activity are much more severe.This is due to the fact that the Turkish economy which was a closed economy before 1980s become gradually more open thereafter. When the general structure of the economy is considered from Fig. 8, we see that at the beginning of 1970s the Turkish economy is dominated by the services and agriculture sectors. However, during the study period the share of agriculture sector continuously declines from $31 \%$ to $11 \%$ and share of industry. 


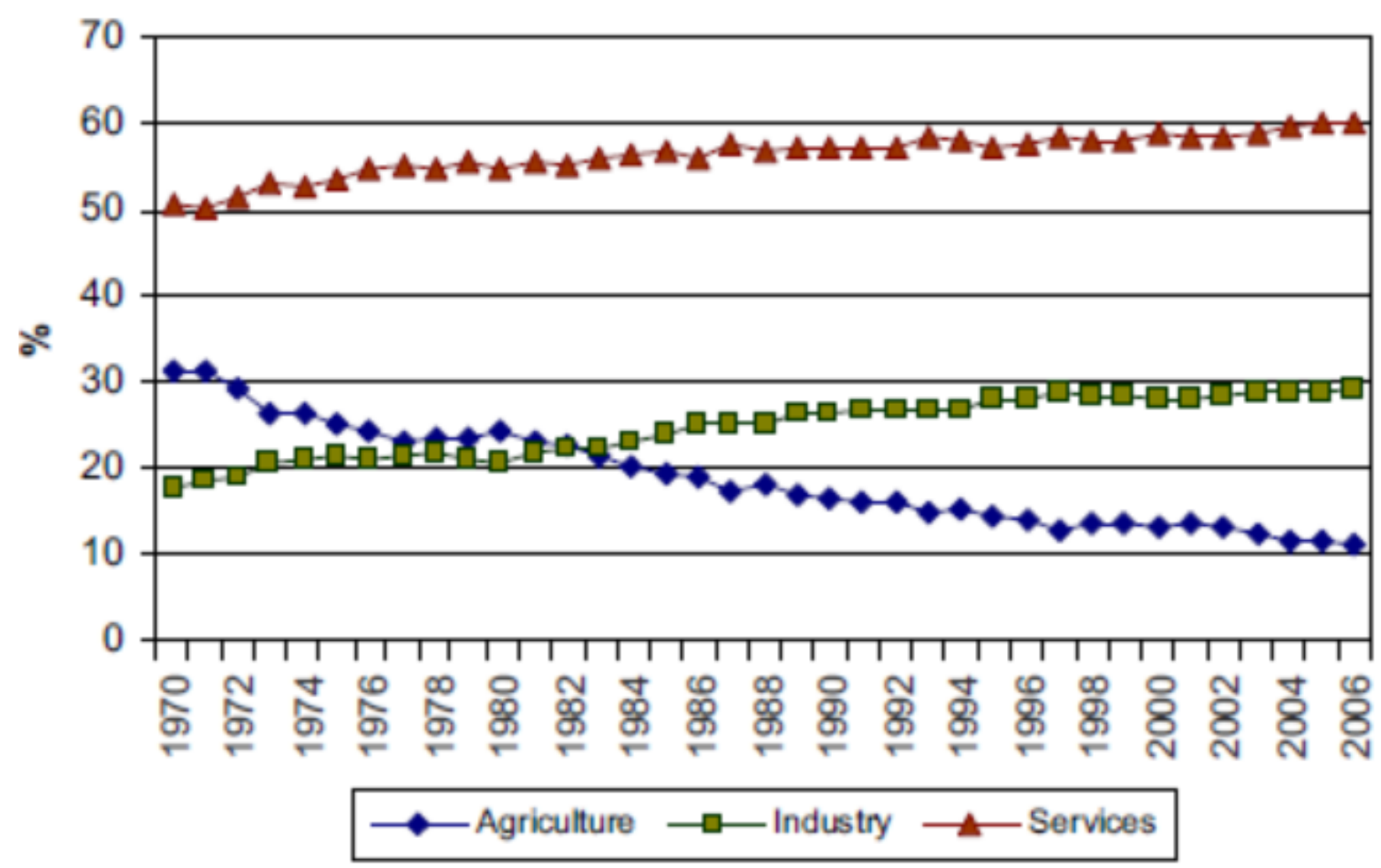

Fig. 7. Shares of sectors in total economic activity

\subsection{The structure effect on industries}

The structure effect on industry is the most effective one followed by services and agriculture (Fig. 8). Industry is positive in 12 years (1981-1986, 1989, 1991, 1993 and 1995-1997) and services are positive in 13 years (1981, 1983-1985, 1987, 1989-1990, 1992-1993, 1996-1997, 1999-2000), whereas agriculture is positive only in three years (1990, 1994, 1998). The most consistent structural changes in industry occur positively between 1981 and 1986 and negatively between 1998 and 2000. From 1987 to 1997, it fluctuates between positives and negatives, reaching a maximum at 1995. This indicates that, although insignificant in aggregate decomposition, the most significant structural changes in industry occurred during the beginning of the studied period. This is roughly applicable also for services. However, the most significant structural changes in agriculture occurred during 1989-1990. Before these years, they are all negative, but after these years, they are fluctuating between positives and negatives. 


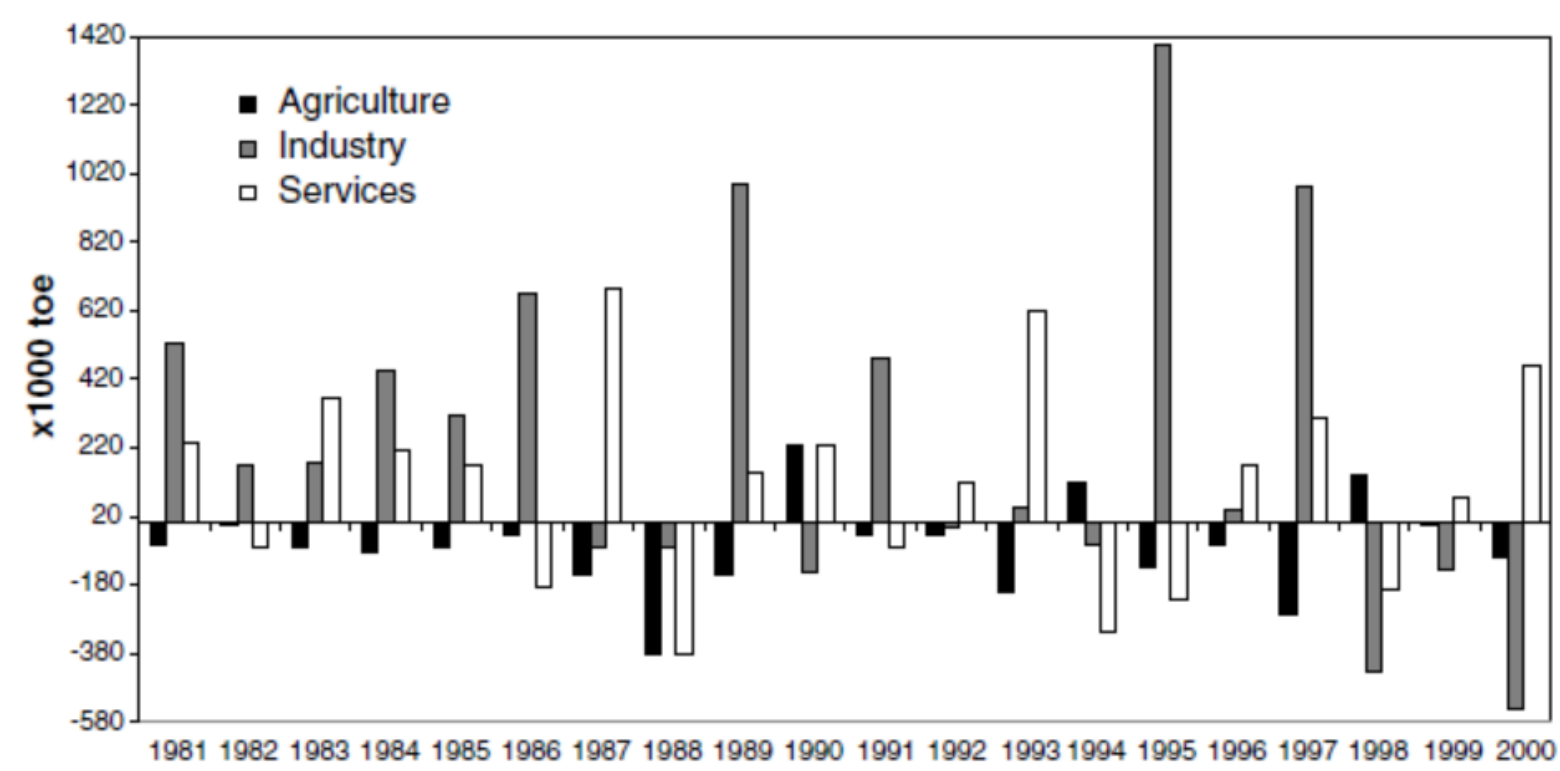

Fig. 8. Decomposition of the structure effect into sectors from 1980 to 2000.

\subsection{Intensity effect}

In contrast to the structural effect, the sectoral decomposition of the intensity effect shows thatservices has the biggest positive and negative effects followed by industry and agriculture (Fig. 9). Services are all negative except for the years 1982, 1988, 1994-1995 and 1999, but agriculture is all positive except for the years 1988, 1990, 1992, 1998 and 2000. On the other hand, industry is positive in 12 years $(1982,1985,1987,1989-1991,1994,1996-2000)$, resulting in an increasing pattern in intensity values. In the years 1982, 1988-1989, 1994 and 1999, when the intensity effect is positive in the aggregate decomposition (see Fig. 6), all sectors are positive except for the year 1988. 


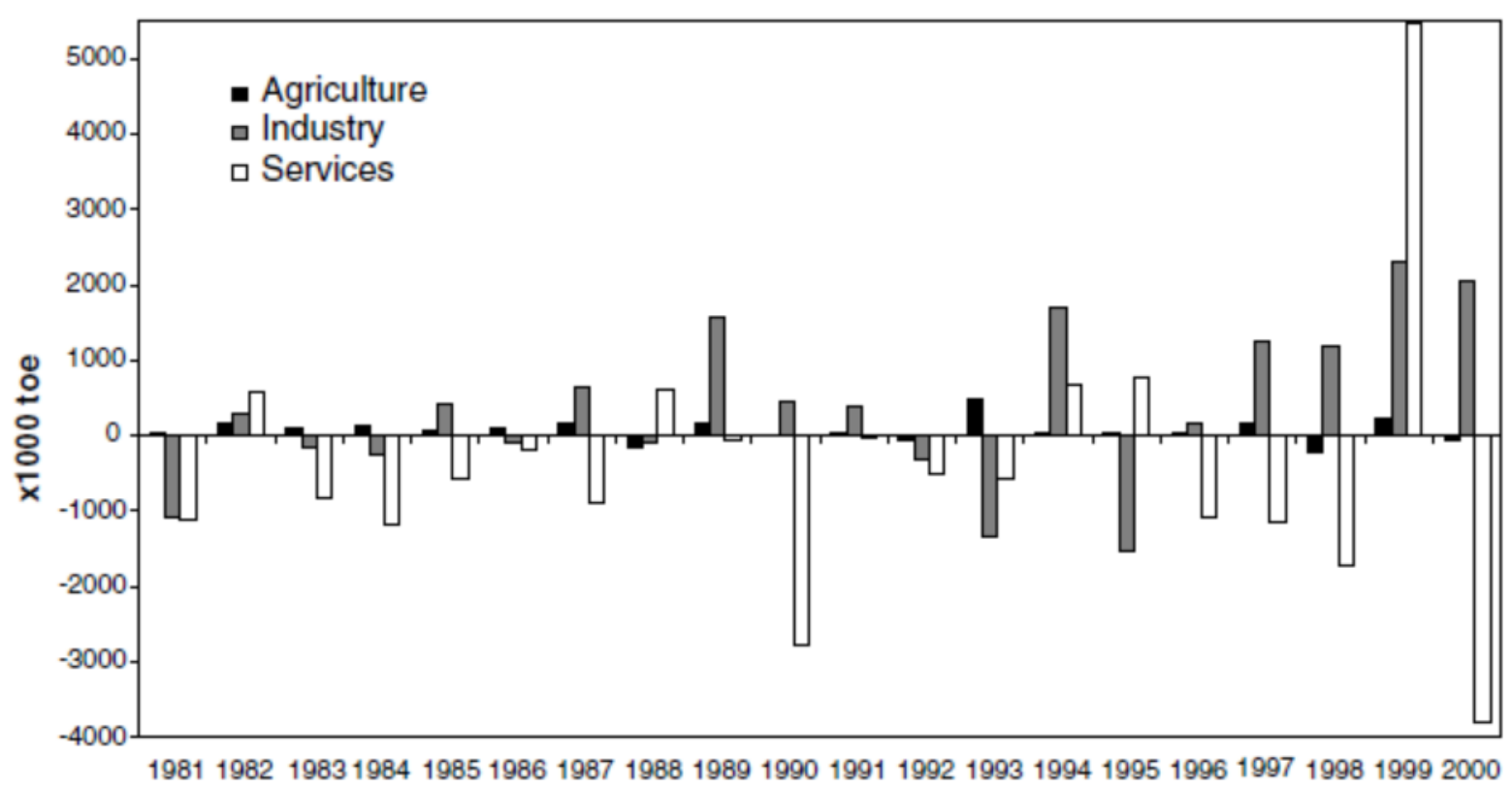

Fig. 9. Decomposition of the intensity effect into sectors from 1980 to 2000.

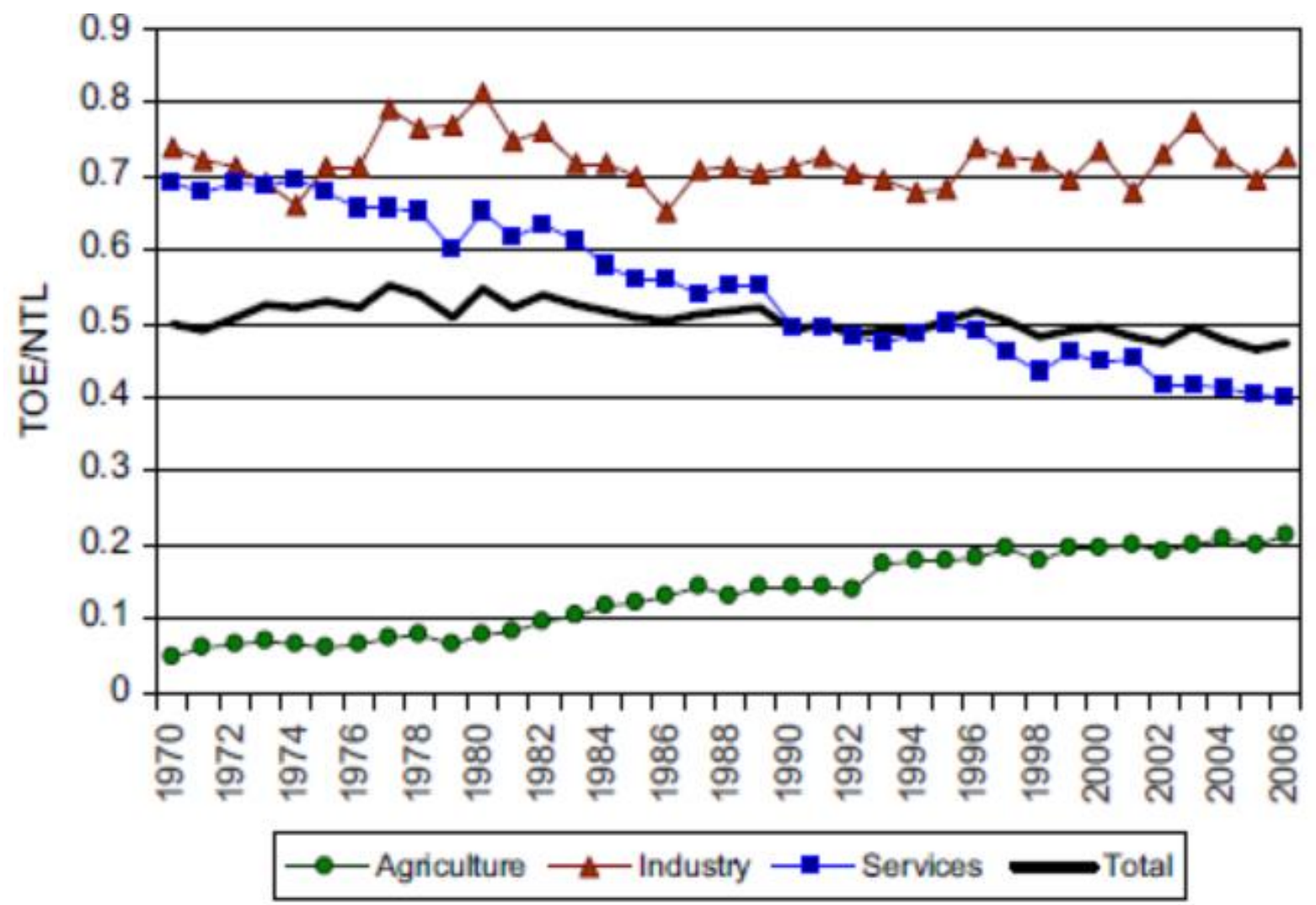

Fig. 10. Energy intensities

The aggregate and sectoral decomposition analyses can, therefore, be summarized as follows: (1) the major contributing effect of the primary energy consumption in the Turkish economy from 1980 to 2000 is the production effect, and the structure and intensity effects are 
insignificant; (2) the Turkish economy can be separated into three relatively stable periods between 1983-1987, 1990-1993 and 1995-1997, each one characterizing positive production and structural effects but negative intensity effects; (3) the most prominent changes in the sectoral energy use pattern in the Turkish economy appears to occur during 1982 and 19881989 and between these periods, while the 1994 and 1998-2000 breaks are directly related to the economic crises.

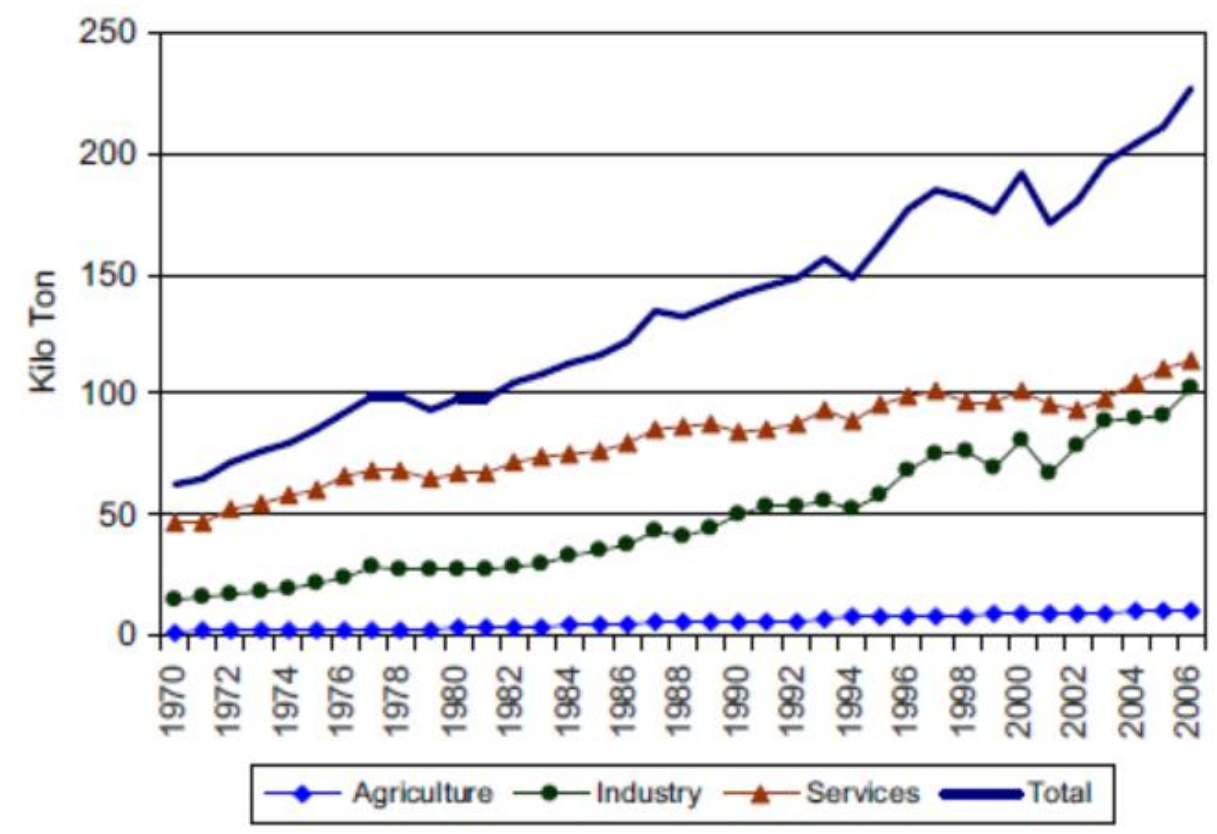

Fig. 11. CO2 emissions

\section{Results and discussion}

In this study, the changes in GHG emissions of four combustion sectors in Turkey were analyzed by the LMDI method that is the complete decomposition method to identify and analyze the factors for reach GHG emissions reduction goals and determined to achieve a lowcarbon transition for Turkey. A comprehensive and detailed analysis of GHG emissions of Turkey for four fuel combustion sectors during 1998-2017 was illustrated based on the LMDI method. This method makes it possible to differentiate the changes in greenhouse gas emissions on a sectoral basis to the activity effect, structural effect, intensity effect, energy-mix effect, and emission-factor effects, which are determined as the factors affecting the emission. This research might describe the major results as described in the following: 
Energy conservation and efficiency are one of the key components of Turkey's 2023 national strategic priorities and energy policies, such as ensuring the protection of energy demand, decreasing the external dependency threats, protecting the environment and rising the effectiveness of combating climate change[32] From 2001 through 2008, there was a favorable declining energy intensity for four energy-intensive industries. After the global economic crisis in 2008, the tendency of energy intensity of manufacturing, commercial and agricultural sectors have stayed on the same level whereas the energy intensity of the transport sector reversed and has started to tremendous increase so far. Policymakers should investigate and try to find and solve the reasons behind these most important problems. Moreover, Turkey could set more ambitious measurable energy efficiency objectives in the transport, agricultural and other energy-intensive sectors.

As the installation of capacity-efficient production equipment is added, it will be crucial to increase industry efficiency and reduce fuel requirements and greenhouse gas emissions. According to the results obtained in this study, the proposed policies mentioned above would have active effects to reduce emissions in Turkey.

It should be noted that the energy intensity of the Turkish manufacturing and commercial industries decreased respectively by 39.3 and $11.5 \mathrm{Mt}$ GHG. Unfortunately, there is no progress on the energy intensity of the transport sector and it causes $10 \mathrm{Mt} \mathrm{CO} 2$ emissions increasing.

The results of the decomposition analyses confirm the economic programs of the governments, which are traditionally separated into three periods as 1980-1983, 1983-1987 and 1988 onwards. The Stabilization Program, also called the "24 January Decisions", which was announced during the beginning of the 1980-1983 period, included a series of economic policy changes aimed at stabilization, liberalization and integration into the worlds. During the 19831987 period, the strong inward orientation of Turkeys trade and industrialization changed into an outward orientation coupled with a good integration with the international markets[33]. The reason why this period is also known as "the golden years"' is related to the outstanding success in export performance, well above the rate of growth of world trade and exports by the newly industrializing countries.

The increasing trends in the yields of agricultural products are usually attributed to mechanization of the sector. In general, the number of modern equipments increases as the number of primitive equipments decrease after 1950, but the biggest changes occurred during 1987-1988, 1990-1991 and 1996-1997. During 1987-1988, wooden plows and animal plows decreased $13.7 \%$ and $2.7 \%$, respectively. During 1990-1991, wooden plows (11.7\%) and 
animal plows (7.4\%) decreased, but fertilizer distributors increased 5.7\%. During 1996-1997, wooden plows (24.8\%), animal plows (20.7\%) and threshers (7.9\%) decreased, while fertilizer distributors $(13.5 \%)$, four wheel tractors $(8.3 \%)$ and moldboard plows $(5.7 \%)$ increased.

This study shows that the sectoral energy use in Turkey from 1980 to 2000 has undergone significant changes owing to the transformation from an agricultural to an industrial economy enhanced by rapid urbanization between 1983 and 1987. However, the country is still in its early stage of development and energy demand should be increasing faster than national income until the energy intensity of the country reaches a peak.

The major driving force to improve the energy-economy relationship of the Turkish economy appears to be governmental policies. Single party governments usually have more power to implement development policies than coalition governments. These policies should include changes in the structure of final energy demand, increases in the efficiency of materials and energy use and the substitution of materials and fuels that are more efficient.

The energy efficiency in Turkish industry is traditionally low compared to other similar countries [38] but can be increased by some policy implications [14]. Some studies clearly showed that Turkey can reduce emissions considerably without slowing economic growth dramatically[34].

Finally, decomposition analyses of total primary energy consumption into production, structure and intensity effects of the Turkish economy from 1980 to 2000 offer useful tools for a better understanding of overall and sectoral changes. However, further decomposition into secondary and tertiary sectors is definitely needed for detailed investigations.

\section{References}

[1] M. Wang and C. Feng, "Decomposition of energy-related CO2 emissions in China: An empirical analysis based on provincial panel data of three sectors," Appl. Energy, vol. 190, pp. 772-787, 2017, doi: 10.1016/j.apenergy.2017.01.007.

[2] D. R. Headrick, "Climate change: Debate and reality," Int. Rev. Environ. Hist., vol. 5, no. 1, pp. 43-60, 2019, doi: 10.22459/ireh.05.01.2019.04.

[3] IPCC, "Climate Change 2014 Synthesis Report," IPCC, Switzerland, 2015. [Online]. Available: https://archive.ipcc.ch/pdf/assessmentreport/ar5/syr/SYR_AR5_FINAL_full_wcover.pdf.

[4] TURKSTAT, "Turkish Greenhouse gas inventory report 1990-2017," TURKSTAT, Ankara, 2019.

[5] OECD, OECD Environmental Performance Reviews: Turkey 2019. OECD, 2019. 
[6] B. W. Ang, "The LMDI approach to decomposition analysis: A practical guide," Energy Policy, vol. 33, no. 7, pp. 867-871, 2005, doi: 10.1016/j.enpol.2003.10.010.

[7] E. Akbostanci, G. I. Tunç, and S. Türüt-Aşik, "CO2 emissions of Turkish manufacturing industry: A decomposition analysis," Appl. Energy, vol. 88, no. 6, pp. 2273-2278, 2011, doi: 10.1016/j.apenergy.2010.12.076.

[8] W. Lise, "Decomposition of CO 2 emissions over 1980-2003 in Turkey," Energy Policy, vol. 34, no. 14, pp. 1841-1852, 2006, doi: 10.1016/j.enpol.2004.12.021.

[9] G. Ipek Tunç, S. Türüt-Aşik, and E. Akbostanci, “A decomposition analysis of CO2 emissions from energy use: Turkish case," Energy Policy, vol. 37, no. 11, pp. 46894699, 2009, doi: 10.1016/j.enpol.2009.06.019.

[10] D. González and M. Martínez, "Decomposition analysis of CO2 emissions in the Mexican industrial sector," Energy Sustain. Dev., vol. 16, no. 2, pp. 204-215, 2012, doi: 10.1016/j.esd.2012.01.005.

[11] M. Zhang, X. Liu, W. Wang, and M. Zhou, "Decomposition analysis of CO2 emissions from electricity generation in China," Energy Policy, vol. 52, pp. 159-165, 2013, doi: 10.1016/j.enpol.2012.10.013.

[12] N. V. Emodi and K. J. Boo, "Decomposition analysis of CO2 emissions from electricity generation in Nigeria," Int. J. Energy Econ. Policy, vol. 5, no. 2, pp. 565$573,2015$.

[13] A. K. Sumabat et al., "Decomposition analysis of Philippine CO2 emissions from fuel combustion and electricity generation," Appl. Energy, vol. 164, pp. 795-804, 2016, doi: 10.1016/j.apenergy.2015.12.023.

[14] E. Akbostanc1, G. İ. Tunç, and S. Türüt-Aşık, "Drivers of fuel based carbon dioxide emissions: The case of Turkey," Renew. Sustain. Energy Rev., vol. 81, no. July 2017, pp. 2599-2608, 2018, doi: 10.1016/j.rser.2017.06.066.

[15] S. Shao, L. Yang, C. Gan, J. Cao, Y. Geng, and D. Guan, "Using an extended LMDI model to explore techno-economic drivers of energy-related industrial CO2 emission changes: A case study for Shanghai (China)," Renew. Sustain. Energy Rev., vol. 55, pp. 516-536, 2016, doi: 10.1016/j.rser.2015.10.081.

[16] V. Ş. Ediger and O. Huvaz, "Examining the sectoral energy use in Turkish economy (1980-2000) with the help of decomposition analysis," Energy Convers. Manag., vol. 47, no. 6, pp. 732-745, 2006, doi: 10.1016/j.enconman.2005.05.022.

[17] J. Chontanawat, P. Wiboonchutikula, and A. Buddhivanich, "An LMDI decomposition analysis of carbon emissions in the Thai manufacturing sector," Energy Reports, vol. 6, pp. 705-710, 2019, doi: 10.1016/j.egyr.2019.09.053.

[18] G. Trotta, "Assessing energy efficiency improvements and related energy security and climate benefits in Finland: An ex post multi-sectoral decomposition analysis," Energy Econ., vol. 86, 2020, doi: 10.1016/j.eneco.2019.104640.

[19] J. Yu, C. Shao, C. Xue, and H. Hu, "China's aircraft-related CO2 emissions: Decomposition analysis, decoupling status, and future trends," Energy Policy, vol. 138, no. January, p. 111215, 2020, doi: 10.1016/j.enpol.2019.111215.

[20] Y. Bu, E. Wang, J. Bai, and Q. Shi, "Spatial pattern and driving factors for interprovincial natural gas consumption in China: Based on SNA and LMDI," J. Clean. Prod., vol. 263, p. 121392, 2020, doi: 10.1016/j.jclepro.2020.121392.

[21] J. Zhang, Z. Fan, Y. Chen, J. Gao, and W. Liu, "Decomposition and decoupling analysis of carbon dioxide emissions from economic growth in the context of China and the ASEAN countries," Sci. Total Environ., vol. 714, p. 136649, Apr. 2020, doi: 10.1016/j.scitotenv.2020.136649.

[22] W. Zhang, X. Tang, G. Yang, and D. Zha, "Decomposition of CO2 emission intensity in Chinese MIs through a development mode extended LMDI method combined with a 
production-theoretical approach," Sci. Total Environ., vol. 702, 2020, doi: 10.1016/j.scitotenv.2019.134787.

[23] Y. Qian, H. Cao, and S. Huang, "Decoupling and decomposition analysis of industrial sulfur dioxide emissions from the industrial economy in 30 Chinese provinces," $J$. Environ. Manage., vol. 260, no. September 2019, 2020, doi: 10.1016/j.jenvman.2020.110142.

[24] Y. Song, M. Zhang, and C. Shan, "Research on the decoupling trend and mitigation potential of CO2 emissions from China' s transport sector," Energy, vol. 183, pp. 837843, 2019, doi: 10.1016/j.energy.2019.07.011.

[25] D. Fang, P. Hao, and J. Hao, "Study of the influence mechanism of China's electricity consumption based on multi-period ST-LMDI model," Energy, vol. 170, pp. 730-743, 2019, doi: 10.1016/j.energy.2018.12.212.

[26] F. Li et al., "Changing patterns and determinants of transportation carbon emissions in Chinese cities," Energy, vol. 174, pp. 562-575, 2019, doi: 10.1016/j.energy.2019.02.179.

[27] S. Jiang, Y. Zhu, G. He, Q. Wang, and Y. Lu, "Factors influencing China's nonresidential power consumption: Estimation using the Kaya-LMDI methods," Energy, p. 117719, 2020, doi: 10.1016/j.energy.2020.117719.

[28] L. Jiang, S. He, X. Tian, B. Zhang, and H. Zhou, "Energy use embodied in international trade of 39 countries: Spatial transfer patterns and driving factors," Energy, vol. 195, p. 116988, 2020, doi: 10.1016/j.energy.2020.116988.

[29] B. W. Ang, "Decomposition analysis for policymaking in energy: Which is the preferred method?," Energy Policy, vol. 32, no. 9, pp. 1131-1139, 2004, doi: 10.1016/S0301-4215(03)00076-4.

[30] IPCC, 2006 IPCC Guidelines for National Greenhouse Gas Inventories, vol. 2 Energy, no. 4. Japan: Institute for Global Environmental Strategies (IGES), 2006.

[31] Republic of Turkey Ministry of Environment and Urbanization, "Seventh National Communication of Turkey under the UNFCCC," Ankara, 2018. [Online]. Available: https://unfccc.int/sites/default/files/resource/496715_Turkey-NC7-1-7th National Communication of Turkey.pdf.

[32] Republic of Turkey Ministry of Energy and Natural Resources (MENR), National energy efficiency action plan (NEEAP) 2017-2023. Ankara, 2018.

[33] B. W. Ang and K.-H. Choi, "Decomposition of Aggregate Energy and Gas Emission Intensities for Industry: A Refined Divisia Index Method," Energy J., vol. 18, no. 3, pp. 59-73, 1997, [Online]. Available: http://www.jstor.org/stable/41322738.

[34] Y. Arıkan and G. Kumbaroğlu, "Endogenising emission taxes: A general equilibrium type optimisation model applied for Turkey," Energy Policy, vol. 29, no. 12, pp. 10451056, 2001, doi: https://doi.org/10.1016/S0301-4215(01)00032-5. 